\title{
Increased Hepatic Mitochondrial Capacity in Rats with Hydroxy-cobalamin[c-lactam]-induced Methylmalonic Aciduria
}

\author{
Stephan Krahenbuhl, " Durwood B. Ray, ${ }^{\ddagger}$ Sally P. Stabler, ${ }^{5}$ Robert H. Allen, ${ }^{5}$ and Eric P. Brass ${ }^{*}$ \\ ${ }^{*}$ Departments of Medicine and Pharmacology, Case Western Reserve University, Cleveland, Ohio $44106 ;{ }^{\ddagger}$ Department of Biochemistry, \\ Oral Roberts University Medical School, Tulsa, Oklahoma 74171; and ${ }^{\S}$ Department of Medicine, \\ University of Colorado Health Sciences Center, Denver, Colorado 80262
}

\section{Abstract}

Treatment of rats with the vitamin B12 analogue hydroxy-cobalamin[c-lactam] (HCCL) impairs methylmalonyl-CoA mutase function and leads to methylmalonic aciduria due to intracellular accumulation of propionyl and methylmalonyl-CoA. Since accumulation of these acyl-CoAs disrupts normal cellular regulation, the present investigation characterized metabolism in hepatocytes and liver mitochondria from rats treated subcutaneously with HCCL or saline (control) by osmotic minipump. Consistent with decreased methylmalonyl-CoA mutase activity, ${ }^{14} \mathrm{CO}_{2}$ production from $1-{ }^{14} \mathrm{C}$-propionate (1 $\mathrm{mM}$ ) was decreased by $76 \%$ and $82 \%$ after $2-3$ wk and 5-6 wk of HCCL treatment, respectively. In contrast, after 5-6 wk of HCCL treatment, ${ }^{14} \mathrm{CO}_{2}$ production from $1-{ }^{14} \mathrm{C}$-pyruvate (10 $\mathrm{mM})$ and $1-{ }^{14} \mathrm{C}$-palmitate $(0.8 \mathrm{mM})$ were increased by $45 \%$ and $49 \%$, respectively. In isolated liver mitochondria, state 3 oxidation rates were unchanged or decreased, and activities of the mitochondrial enzymes, citrate synthetase, succinate dehydrogenase, carnitine palmitoyltransferase, and glutamate dehydrogenase (expressed per milligram mitochondrial protein) were unaffected by HCCL treatment. In contrast, activities of the same enzymes were significantly increased in both liver homogenate (expressed per gram liver) and isolated hepatocytes (expressed per $10^{6}$ cells) from HCCL-treated rats. The mitochondrial protein per gram liver, calculated on the basis of the recovery of the mitochondrial enzymes, increased by $39 \%$ in 5-6 wk HCCL-treated rats. Activities of lactate dehydrogenase, catalase, cyanide-insensitive palmitoyl-CoA oxidation, and arylsulfatase $A$ in liver were not affected by HCCL treatment. Hepatic levels of mitochondrial mRNAs were elevated up to 10-fold in HCCL-treated animals as assessed by Northern blot analysis. Thus, HCCL treatment is associated with enhanced mitochondrial oxidative capacity and an increased mitochondrial protein content per gram liver. Increased mitochondrial oxidative capacity may be a compensatory mechanism in response to the metabolic insult induced by HCCL administration. (J. Clin. Invest. 1990. 86:2054-2061.) Key words: organic acidurias • animal model • cobalamin analogues - mitochondrial function • mitochondrial biogenesis

Address correspondence to Dr. Eric P. Brass, Department of Medicine, Division of Clinical Pharmacology, Case Western Reserve University, Cleveland, Ohio 44106.

Received for publication 23 February 1990 and in revised form 21 May 1990.

J. Clin. Invest.

(C) The American Society for Clinical Investigation, Inc.

0021-9738/90/12/2054/08 \$2.00

Volume 86, December 1990, 2054-2061

\section{Introduction}

Vitamin B12 (cobalamin) deficiency leads to decreased activity of the cobalamin-requiring enzymes methylmalonyl-CoA mutase and methionine synthetase (1). Decreased activity of methylmalonyl-CoA mutase results in accumulation of methylmalonyl- and propionyl-CoA, and methylmalonic aciduria (2-4). This defect is analogous to the metabolic defect in patients with hereditary methylmalonic acidurias. The vitamin B12-deficient rat has provided a useful animal model for the human methylmalonic acidurias and allowed the investigation of hepatic metabolism in the presence of this specific, metabolic insult (4-6). Dietary vitamin B12 deficiency is difficult to achieve, and the resulting metabolic defect shows a high variability between treated animals $(7,8)$. An alternative methodology to induce decreased activity of methylmalonyl-CoA mutase is treatment with hydroxy-cobalamin [c-lactam] (HCCL), ${ }^{1}$ a synthetic vitamin B12 analogue (4-6). Rats treated with HCCL develop decreased hepatic vitamin B12 levels (4), decreased methylmalonyl-CoA mutase and methionine synthetase activity (6), and decreased propionate metabolism with an increased renal excretion of methylmalonic acid (4-6).

Increased hepatocellular propionyl and methylmalonylCoA concentrations inhibit several metabolic activities, including gluconeogenesis $(9,10)$, urea synthesis $(9,11)$ fatty acid oxidation $(11,12)$ and pyruvate decarboxylation $(13,14)$. In contrast, in rats with chronic accumulation of propionyl and methylmalonyl-CoA induced by dietary vitamin B12 deficiency, gluconeogenetic and ketogenetic responses to fasting were intact in vivo (4), suggesting compensatory mechanisms that mitigate the toxic effects of accumulated acyl-CoAs. One compensatory mechanism in rats with dietary and functional vitamin B12 deficiency is increased hepatic total CoA concentration $(4,15)$.

To further study hepatic metabolism under conditions of impaired methylmalonyl-CoA mutase activity, hepatic mitochondrial function in HCCL- and saline-treated rats was characterized. Mitochondrial function was quantified by measurement of fuel oxidation rates in isolated hepatocytes and mitochondria. In addition, activities of mitochondrial and extramitochondrial enzymes were determined in isolated mitochondria, liver homogenates, and the hepatocyte preparations. Levels of mitochondrial RNA were determined by Northern blot analysis using as a probe whole mouse mitochondrial DNA. The results demonstrate that treatment with HCCL is associated with a significant increase in mitochondrial protein per gram of liver tissue and hepatic mitochondrial oxidative capacity.

1. Abbreviations used in this paper: HCCL, hydroxy-cobalamin[c-lactam]; MOPS, morpholinopropane sulfonic acid. 


\section{Methods}

Animals. Male Fischer 344 rats purchased from Charles River Breeding Laboratories (Portage, MI) were used for all experiments. Two to three rats were housed per cage with free access to water and rat chow (Lab Chows; Purina Mills Inc., St. Louis, MO). After an acclimation period of 1 wk, an osmotic minipump (model 2002; Alza Corporation, Palo Alto, CA) containing either saline (control animals) or HCCL (treated animals) was implanted subcutaneously in each animal. HCCL was delivered at a rate of $2 \mu \mathrm{g} / \mathrm{h}$. Each animal not used in the studies during weeks $2-3$ received a second minipump (contents identical to the first minipump) $21 \mathrm{~d}$ after the initial implantation. At the time point of the initial pump implantation the rats weighed $250 \pm 20 \mathrm{~g}$ $(n=25)$. After a treatment period of $2-3 \mathrm{wk}$, control animals weighed $310 \pm 20 \mathrm{~g}(n=6)$ and HCCL-treated animals $300 \pm 20 \mathrm{~g}(n=6)$, respectively. After 5-6 wk, control animals weighed $330 \pm 30 \mathrm{~g}(n=6)$ and HCCL-treated animals $340 \pm 20 \mathrm{~g}(n=7)$, respectively.

Hepatocyte isolation. Hepatocytes were prepared from fed rats by the method of Berry and Friend (16) with the modifications described previously (17). All hepatocyte preparations were started at 07:00. Isolated hepatocytes used in the current studies were $91 \pm 3 \%(n=13)$ viable based on trypan blue exclusion, contained $3.41 \pm 0.87 \mathrm{mg}$ protein $/ 10^{6}$ cells $(n=13)$, and had a wet weight of $16.5 \pm 3.1 \mathrm{mg} / 10^{6}$ cells $(n=13)$. Hepatocytes from control and HCCL-treated animals did not differ with respect to any of the parameters assessed.

Hepatocyte metabolism. ${ }^{14} \mathrm{CO}_{2}$, and ${ }^{14} \mathrm{C}$-glucose formation from ${ }^{14} \mathrm{C}$-labeled substrates by the isolated hepatocytes were measured in 25-ml Erlenmeyer flasks equipped with sidearms and centerwells. Incubation procedures were as detailed elsewhere (18). The incubations contained hepatocytes $\left(2.42 \pm 0.69 \times 10^{6} \mathrm{cells} / \mathrm{ml} ; n=13\right), 1 \%$ defatted BSA (wt/vol), $124 \mathrm{mM} \mathrm{NaCl}, 3.8 \mathrm{mM} \mathrm{KCl}, 0.95 \mathrm{mM} \mathrm{KH}_{2} \mathrm{PO}_{4}, 1.9$ $\mathrm{mM} \mathrm{MgSO}_{4}, 0.90 \mathrm{mM} \mathrm{CaCl}_{2}, 20 \mathrm{mM} \mathrm{NaHCO}_{3}, 8 \mathrm{mM}$ Tris(hydroxymethyl) aminomethane, $3.2 \mathrm{mM}$ glucose, and other compounds as detailed in the individual experiments. The total incubation volume was $2.5 \mathrm{ml}$. The incubations were conducted under $95 \% \mathrm{O}_{2} / 5 \% \mathrm{CO}_{2}$ at $37^{\circ} \mathrm{C}$. After a $30-\mathrm{min}$ preincubation, the substrates were added at time 0 . The specific activities of the substrates were individually determined for each experiment and averaged $81 \mathrm{dpm} / \mathrm{nmol}$ for $1.0 \mathrm{mM} 1-{ }^{14} \mathrm{C}$ propionate, $22 \mathrm{dpm} / \mathrm{nmol}$ for $10.0 \mathrm{mM} 1-{ }^{14} \mathrm{C}$-propionate, $5.0 \mathrm{dpm} /$ nmol for $10.0 \mathrm{mM} 1{ }^{14} \mathrm{C}$-pyruvate, and $110 \mathrm{dpm} / \mathrm{nmol}$ for $0.8 \mathrm{mM}$ $1-{ }^{14} \mathrm{C}$-palmitate. The reactions were terminated by the addition of perchloric acid to yield a final concentration of $3 \%(\mathrm{vol} / \mathrm{vol})$ in the incubations.

${ }^{14} \mathrm{CO}_{2}$ was collected in the flask centerwells containing $0.3 \mathrm{ml}$ ethanolamine/ethylene glycol monomethyl ether $\left(1: 2\right.$, vol/vol). ${ }^{14} \mathrm{C}$ contained in the incubations terminated at time 0 was subtracted to provide net ${ }^{14} \mathrm{CO}_{2}$ production. The amount of $1{ }^{14} \mathrm{C}$-substrate used for $\mathrm{CO}_{2}$ formation was calculated as ${ }^{14} \mathrm{CO}_{2}$ production (net dpm) divided by the specific activity of the substrate used. For propionate, ${ }^{14} \mathrm{CO}_{2}$ arising from tricarboxylic acid cycle activity was estimated by subtracting ${ }^{14} \mathrm{C}$-glucose from net ${ }^{14} \mathrm{CO}_{2}$ measured under identical conditions (18).

For the quantification of ${ }^{14} \mathrm{C}$-glucose production from $1-{ }^{14} \mathrm{C}$-pyruvate, aliquots were removed from the incubations at time 0 and after $30 \mathrm{~min}$ and added to an equal volume of cold $6 \%$ perchloric acid (vol/vol). After alkaline hydrolysis (to hydrolyze ${ }^{14} \mathrm{C}$-acylcarnitines) the samples were neutralized and passed through a Dowex $1 \times 8 \mathrm{Cl}^{-}$ form mini-column $(18,19)$. Net $1-{ }^{14} \mathrm{C}$-substrate used for glucose production was calculated as ${ }^{14} \mathrm{C}$-glucose (net dpm) divided by the specific activity of the substrate.

Mitochondrial isolation and incubation. Liver mitochondria were isolated as described by Hoppel et al. (20). Briefly, fed rats were killed by decapitation between 08:00 and 09:00 a.m. Liver weights were $3.7 \pm 0.2$ and $3.3 \pm 0.2 \mathrm{~g} / 100 \mathrm{~g}$ body weight in $2-3$ wk treated control $(n$ $=3$ ) and HCCL-treated $(n=3)$ animals, respectively, and $3.3 \pm 0.2$ and $3.5 \pm 0.2 \mathrm{~g} / 100 \mathrm{~g}$ body weight in 5-6 wk treated control $(n=3)$ and HCCL-treated animals $(n=3)$, respectively. The liver was quickly exposed and a freeze-clamped sample was taken (clamps cooled in acetone/dry ice). The remainder of the liver was removed and placed in ice-cold MSM-buffer (220 mM mannitol, $70 \mathrm{mM}$ sucrose, $5 \mathrm{mM}$ MOPS; pH 7.4). The liver was rinsed, blotted, weighed, minced, and washed with cold MSM. A $10 \%$ suspension (wt/vol) of the minced liver in cold MSM containing $2 \mathrm{mM}$ EDTA was homogenized in a PotterElvejhelm homogenizer with a loose-fitting pestle. Nuclei and cell debris were removed by centrifugation at $700 \mathrm{~g}$ for $10 \mathrm{~min}$, and mitochondria were isolated by centrifugation of the resulting supernatant at $7,000 \mathrm{~g}$ for $10 \mathrm{~min}$. The resulting mitochondrial pellet was washed twice with MSM and diluted to contain $\sim 5 \mathrm{mg}$ mitochondrial protein per milliliter.

Mitochondrial oxygen consumption was measured in a chamber equipped with a Clark type electrode (Yellow Springs Instruments, Yellow Springs, $\mathrm{OH}$ ) at $30^{\circ} \mathrm{C}$. The incubations contained $2 \mathrm{mg}$ mitochondrial protein in $80 \mathrm{mM} \mathrm{KCl}, 50 \mathrm{mM}$ MOPS, $1 \mathrm{mM}$ EGTA, $5 \mathrm{mM}$ $\mathrm{KH}_{2} \mathrm{PO}_{4}, \mathrm{pH}$ 7.4. Defatted BSA $1 \mathrm{mg} / \mathrm{ml}$ (wt/vol) was added to the incubations containing palmitoyl-L-carnitine as substrate. The final volume was $500 \mu \mathrm{l}$ for the incubations with palmitoyl-L-carnitine as substrate and $1,000 \mu \mathrm{l}$ when other substrates were used. State 3 respiration was initiated by the addition of adenosine diphosphate (ADP) to the incubations (final concentration $150 \mathrm{nmol} / \mathrm{ml}$ ). State 3 and state 4 respirations were defined according to Chance (21) as ADP-stimulated and ADP-limited respiration, respectively. Respiratory control (ratio of state 3 to state 4 rates of oxygen consumption) and ADP/O ratios (ratio of ADP utilized and oxygen utilized) were calculated according to Estabrook (22).

Enzyme assays and protein determination. Cells and mitochondria were solubilized by treatment with $5 \%$ cholate $(2 \mathrm{mg}$ mitochondrial protein to $100 \mu \mathrm{l}$ of $5 \%$ cholate, or $100 \mu \mathrm{l}$ liver homogenate or isolated hepatocytes to $100 \mu$ l cholate $5 \%$ ), with the exception of samples for the determination of cyanide-insensitive palmitoyl-CoA oxidation, where liver homogenate was used directly. Citrate synthetase (23), glutamate dehydrogenase (24), and succinate dehydrogenase activities (25) were quantified by spectrophotometric methods using established methodologies. Carnitine palmitoyltransferase activity was measured as the CoA-dependent release of $\left[\mathrm{Me}-{ }^{14} \mathrm{C}\right]$ carnitine from palmitoyl[ $\left.\mathrm{Me}-{ }^{14} \mathrm{C}\right]-$ carnitine (26). Palmitoylcarnitine hydrolase activity was determined using a blank containing no $\mathrm{CoA}$ and substracted to yield carnitine palmitoyltransferase activity. Catalase activity (27), and cyanide-insensitive palmitoyl-CoA oxidation (28) were determined as peroxisomal markers, arylsulfatase A activity as a lysosomal marker (29), and lactate dehydrogenase activity as a soluble cytoplasmatic enzyme (30). Enzyme activities are expressed as nanomoles per minute per milligram protein, per gram liver or per $10^{6}$ cells with the exception of catalase, where the first order reaction constant is given. Protein concentrations were determined using the biuret method using BSA as standard (31).

Isolation and profiling of mitochondrial RNA. Total RNA was isolated from liver homogenate by centrifugation on a cesium chloride gradient as described previously (32). Purified RNA was quantified by absorbance at $260 \mathrm{~nm}$, assuming an extinction coefficient of 20 $\mathrm{ml} / \mathrm{mg} / \mathrm{cm}$. The amount of RNA isolated was not different between control and treated animals, averaging 4.5 $\pm 1.1(n=3)$ and 3.9 \pm 0.4 $\mu \mathrm{g} / \mathrm{mg}$ liver wet weight $(n=3)$ for control and 5-6 wk HCCL-treated animals, respectively. The $A_{269} / A_{280}$ ratio of the RNA preparations averaged $1.97 \pm 0.10$. RNA isolated from each animal $(20 \mu \mathrm{g})$ was placed onto a $1.1 \%$ denaturating agarose gel and size fractionated by electrophoresis for $16 \mathrm{~h}$ at $22 \mathrm{~V}$ (32). After ultraviolet detection of the RNA bands to ensure and document proper separation, the RNA was transferred to a nylon membrane (Stratagene, Inc.) by Vacu Blot (American Bionetics, Inc.) transfer. Proper transfer of the RNA from the gel to the nylon membrane was verified by staining with ethidium bromide. The transferred RNA was probed with a [ $\left.{ }^{32} \mathrm{P}\right] \mathrm{cDNA}$ plasmid (pAM1) that contains the entire mouse mitochondrial genome (33). Hybridization and autoradiography were performed as described previously (32). The membranes were then exposed to $x$-ray films (Kodak $\mathrm{X}$-Omat AR) for autoradiography. The bands on the autoradiographs were quantified on an Ultra Scan Laser Densitometer (model 2202; 
LKB Instruments, Inc., Gaithersburg, MD). The relative radioactivity of each band was determined within the instrumental absorbance ranges that gave linear relationships between radioactivity and absorbance.

Reagents. $1-{ }^{14} \mathrm{C}$-Propionate, $1-{ }^{14} \mathrm{C}$-palmitate and $1-{ }^{14} \mathrm{C}$-pyruvate were purchased from New England Nuclear (Boston, MA). Palmitoyl$\left[\mathrm{Me}-{ }^{14} \mathrm{C}\right] \mathrm{L}$-carnitine and palmitoyl-L-carnitine were prepared by the method of Ziegler et al. (34), and were provided by Dr. Charles L. Hoppel (Case Western Reserve University, Cleveland, $\mathrm{OH}$ ). Collagenase (type II) used for the isolation of hepatocytes was from Worthington Biochemical Corp. (Freehold, NJ). HCCL was prepared by the reduction of the previously synthesized cyanocobalamin analogue (35, 36). Octanoyl- and palmitoyl-CoA, and defatted BSA were purchased from Sigma Chemical Co. (St. Louis, MO). All other chemicals used were of reagent grade.

Statistics. Data are presented as mean \pm standard deviation with $n$ referring to the number of samples analyzed, each from different animals. Data were analyzed by analysis of variance (ANOVA) (37). Student's $t$ test with Bonferroni correction was used to compare individual means in the case of a significant $F$ in the ANOVA (37). Linear regression analysis was performed by the method of least squares (37). $P$ $<0.05$ was considered to be statistically significant.

\section{Results}

Hepatocytes for metabolic studies were isolated from animals treated with saline (control) or HCCL for 2-3 wk or 5-6 wk. Consistent with previous studies $(5),{ }^{14} \mathrm{CO}_{2}$ production from $1-{ }^{14} \mathrm{C}$-propionate $(1 \mathrm{mM})$ was decreased by $83 \%$ in hepatocytes from 5-6-wk HCCL-treated rats as compared with controls, averaging $67.4 \pm 19.4$ and $11.8 \pm 1.3 \mathrm{nmol} / 10^{6}$ hepatocytes $/ 30$ $\min (P<0.05)$ for control $(n=5)$ and HCCL-treated animals $(n=4)$, respectively. In contrast, after 5-6 wk of HCCL treatment, ${ }^{14} \mathrm{CO}_{2}$ production rates from $1{ }^{14} \mathrm{C}$-pyruvate $(10 \mathrm{mM})$ were increased from $710 \pm 160$ in hepatocytes from control animals $(n=6)$ to $1,040 \pm 150 \mathrm{nmol} / 10^{6}$ hepatocytes $/ 30 \mathrm{~min}(P$ $<0.05)$ in hepatocytes from HCCL-treated rats $(n=4)$. Similarly, hepatocyte ${ }^{14} \mathrm{CO}_{2}$ production rates from $1-{ }^{14} \mathrm{C}$-palmitate $(0.8 \mathrm{mM})$ increased $(P<0.05)$ from $7.0 \pm 1.9$ (control animals $n=5$ ) to $10.4 \pm 2.0 \mathrm{nmol} / 10^{6}$ hepatocytes $/ 30 \mathrm{~min}$ (HCCLtreated rats, $n=4)$. In hepatocytes from rats treated with HCCL for $2-3 \mathrm{wk}(n=3),{ }^{14} \mathrm{CO}_{2}$ production from $1-{ }^{14} \mathrm{C}$-pyruvate $(10 \mathrm{mM})$ and $1{ }^{14} \mathrm{C}$-palmitate $(0.8 \mathrm{mM})$ were $790 \pm 60$ and $8.8 \pm 1.0 \mathrm{nmol} / 10^{6}$ hepatocytes $/ 30 \mathrm{~min}$, respectively. In contrast to ${ }^{14} \mathrm{CO}_{2}$ production, ${ }^{14} \mathrm{C}$-glucose production from $1-{ }^{14} \mathrm{C}$ pyruvate was not different in hepatocytes from control animals as compared with hepatocytes from 5-6-wk HCCLtreated animals, averaging $111 \pm 27$ and $135 \pm 32 \mathrm{nmol} / 10^{6}$ hepatocytes/30 $\mathrm{min}$ in control $(n=6)$ and HCCL-treated animals $(n=4)$, respectively.

Oxidative metabolism was further characterized using isolated liver mitochondria from control and HCCL-treated rats. No difference in state 3 oxidation rates was observed between mitochondria from HCCL-treated and control animals with $\beta$-hydroxybutyrate as substrate. State 3 oxygen consumption expressed per milligram mitochondrial protein was reduced by $37 \%$ with palmitoyl-L-carnitine as substrate after $2-3 \mathrm{wk}$, and with pyruvate and palmitoyl-L-carnitine as substrates (by $35 \%$ and $58 \%$, respectively) after 5-6 wk of treatment with HCCL (Table I). Decreasing the palmitoyl-L-carnitine concentration from 80 to 40 and $20 \mu \mathrm{mol} / \mathrm{liter}$ increased state 3 oxygen consumption by mitochondria from HCCL-treated rats by $31 \%$ and $47 \%$ (mean of two determinations), respectively. In
Table I. Oxidative Metabolism by Rat Liver Mitochondria

\begin{tabular}{|c|c|c|c|}
\hline \multirow[b]{2}{*}{ Substrate } & \multirow[b]{2}{*}{$\begin{array}{l}\text { Control } \\
(n=6)\end{array}$} & \multicolumn{2}{|c|}{$\operatorname{HCCL}(n=3)$} \\
\hline & & $\begin{array}{l}\text { Treated } \\
2-3 \mathbf{w k}\end{array}$ & $\begin{array}{l}\text { Treated } \\
5-6 \mathrm{wk}\end{array}$ \\
\hline & \multicolumn{3}{|c|}{ natoms $/ \mathrm{min} / \mathrm{mg}$ mitochondrial protein } \\
\hline \multicolumn{4}{|l|}{ Oxygen consumption state 3} \\
\hline $20 \mathrm{mM} \beta$-hydroxybutyrate & $40.5 \pm 5.5$ & $49.2 \pm 8.0$ & $42.1 \pm 1.0$ \\
\hline $\begin{array}{l}20 \mathrm{mM} \text { pyruvate }+5 \mathrm{mM} \\
\text { malate }\end{array}$ & $48.5 \pm 3.5$ & $40.6 \pm 8.0^{*}$ & $31.4 \pm 4.9^{*}$ \\
\hline \multicolumn{4}{|l|}{$80 \mu \mathrm{M}$ palmitoyl-L-carnitine } \\
\hline$+5 \mathrm{mM}$ malate & $112 \pm 9$ & $71 \pm 17^{*}$ & $47 \pm 2^{*}$ \\
\hline \multicolumn{4}{|l|}{ RCR } \\
\hline $20 \mathrm{mM} \beta$-hydroxybutyrate & $4.5 \pm 1.0$ & $5.7 \pm 0.5$ & $5.5 \pm 0.5$ \\
\hline $\begin{array}{l}20 \mathrm{mM} \text { pyruvate }+5 \mathrm{mM} \\
\text { malate }\end{array}$ & $5.4 \pm 0.9$ & $5.0 \pm 0.8$ & $3.8 \pm 0.7$ \\
\hline \multicolumn{4}{|l|}{$80 \mu \mathrm{m}$ palmitoyl-L-carnitine } \\
\hline$+5 \mathrm{mM}$ malate & $7.5 \pm 1.0$ & $2.7 \pm 0.5^{*}$ & $2.1 \pm 0.4^{*}$ \\
\hline \multicolumn{4}{|l|}{$\mathrm{ADP} / \mathrm{O}$ ratio } \\
\hline $20 \mathrm{mM} \beta$-hydroxybutyrate & $2.5 \pm 0.2$ & $2.5 \pm 0.1$ & $2.5 \pm 0.1$ \\
\hline $\begin{array}{l}20 \text { mM pyruvate }+5 \mathrm{mM} \\
\text { malate }\end{array}$ & $2.7 \pm 0.1$ & $2.5 \pm 0.1$ & $2.7 \pm 0.5$ \\
\hline \multicolumn{4}{|l|}{$80 \mu \mathrm{M}$ palmitoyl-L-carnitine } \\
\hline$+5 \mathrm{mM}$ malate & $2.1 \pm 0.1$ & $1.7 \pm 0.3$ & $1.5 \pm 0.2^{*}$ \\
\hline
\end{tabular}

Mitochondria were isolated from fed animals as described in the text. Oxygen consumption was measured in a 0.5 -ml (palmitoyl-L-carnitine) or a 1-ml chamber ( $\beta$-hydroxybutyrate and pyruvate) equipped with a Clark electrode at $30^{\circ} \mathrm{C}$. Composition of the incubation medium and calculation of the respiratory control ratio (RCR) and ADP/O ratio are described in the text.

${ }^{*} P<0.05$ treated vs. control. No differences were present between the treated groups.

mitochondrial incubations from control rats, lowering the palmitoyl-L-carnitine concentration had no effect on state 3 respiration. State 4 oxidation rates were equal in mitochondrial preparations from control and HCCL-treated rats (data not shown), and thus the respiratory control ratio showed the same

Table II. Enzyme Activities in Isolated Liver Mitochondria

\begin{tabular}{lccc}
\hline & & \multicolumn{2}{c}{ HCCL $(n=3)$} \\
\cline { 3 - 4 } \multicolumn{1}{c}{ Enzyme } & $\begin{array}{c}\text { Control } \\
n\end{array}$ & \multicolumn{2}{c}{$n$ mol/min/mg mitochondrial protein } \\
\cline { 3 - 4 } & $170 \pm 15$ & $179 \pm 2$ & $201 \pm 9^{* \ddagger}$ \\
Citrate synthetase & $171 \pm 27$ & $206 \pm 26$ & $193 \pm 48$ \\
$\begin{array}{l}\text { Glutamate dehydrogenase } \\
\text { Succinate dehydrogenase }\end{array}$ & $43.7 \pm 4.5$ & $42.1 \pm 5.8$ & $40.2 \pm 4.1$ \\
$\begin{array}{l}\text { Carnitine palmitoyl- } \\
\text { transferase }\end{array}$ & $408 \pm 28$ & $417 \pm 38$ & $400 \pm 17$ \\
\hline
\end{tabular}

Isolated liver mitochondria were prepared for the enzyme assays by mixing the volume corresponding to $2 \mathrm{mg}$ mitochondrial protein with $100 \mu$ l of cholate $5 \%(\mathrm{wt} / \mathrm{vol})$ and $0.1 \mathrm{M}$ potassium phosphate buffer, pH 7.2, to bring the volume to $1 \mathrm{ml}$. Enzyme assays were performed as described in the text.

${ }^{*} P<0.05$ treated vs. control.

$\ddagger P<0.05$ between treated groups. 
Table III. Activity of Mitochondrial Enzymes in Liver Homogenates and Isolated Hepatocytes

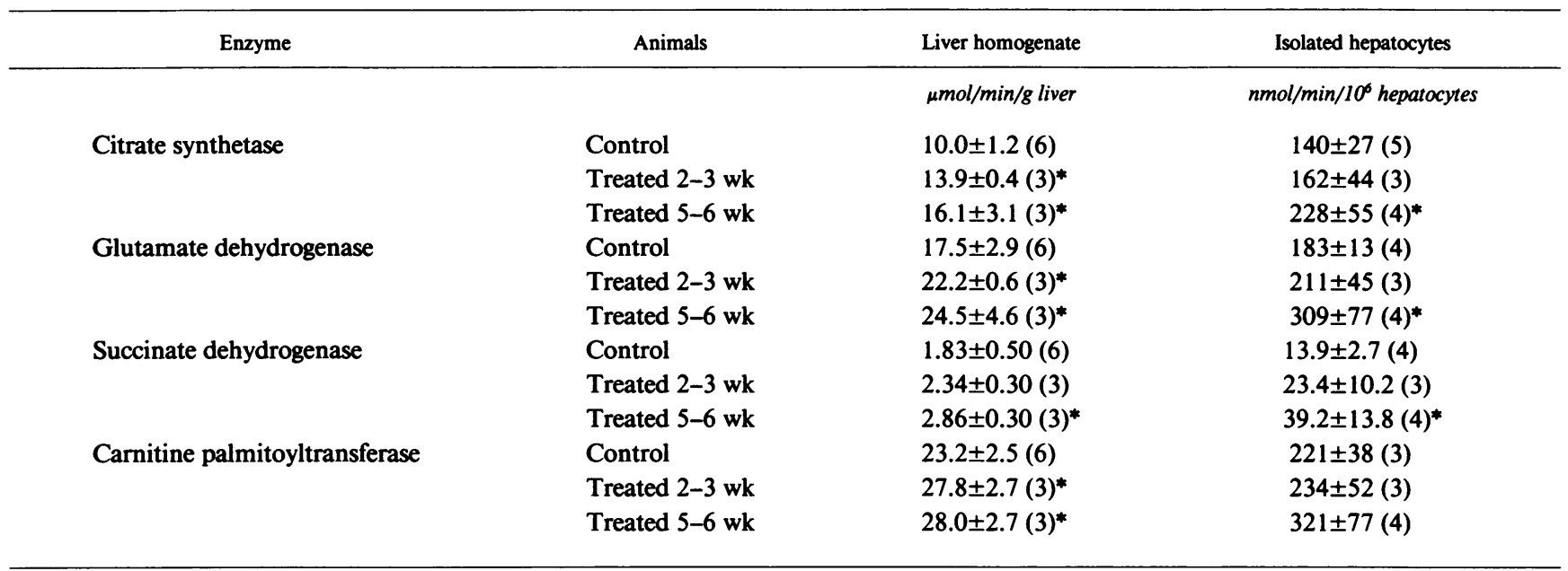

To measure enzyme activities, $100 \mu \mathrm{l}$ liver homogenate or $100 \mu \mathrm{l}$ hepatocyte preparations from control or HCCL-treated animals were mixed with $100 \mu \mathrm{l}$ cholate $5 \%(\mathrm{wt} / \mathrm{vol})$ and $800 \mu \mathrm{l} 0.1 \mathrm{M}$ potassium phosphate, pH 7.2. Enzyme assays were performed as described in the text. Values in parentheses indicate the number of determinations. ${ }^{*} P<0.05$ treated vs. control. No significant differences were present between the treated groups.

pattern as the state 3 oxidation rates. ADP/O ratios were equal in mitochondrial preparations from control and HCCLtreated animals except when palmitoyl-L-carnitine was used as a substrate.

Enhanced pyruvate and palmitate oxidation rates in hepatocytes from HCCL-treated rats, without a corresponding increase per mitochondrial protein, suggested increased mitochondrial content per hepatocyte and per gram wet weight of liver. Activities of the mitochondrial enzymes, citrate synthetase, glutamate dehydrogenase, succinate dehydrogenase, and carnitine palmitoyltransferase, were not different per milligram of mitochondrial protein in treated and control rats, with the exception of a $20 \%$ increase in citrate synthetase activity after 5-6 wk treatment (Table II). However, as seen in Table III, all four mitochondrial enzymes showed increased activity when assayed in the liver homogenate (activity expressed per gram liver) or in isolated hepatocytes (activity expressed per $10^{6}$ cells). Based on the enzyme activities in the mitochondrial preparations and in the liver homogenates, the mitochondrial protein content per gram liver was calculated (Table IV). The use of the four enzymes yielded four estimates of mitochondrial protein content per gram liver, which, when averaged, showed a $39 \%$ increase after 5-6 wk of HCCL treatment. This increase was specific for the mitochondrial compartment as activities of lactate dehydrogenase (a cytosolic enzyme), arylsulfatase A (a lysosomal enzyme), and catalase- and cyanideinsensitive palmitoyl-CoA oxidation (peroxisomal enzyme activities) were all unaffected by HCCL treatment, both in the mitochondrial fraction (data not shown) and per gram liver weight (Table V). The rate of pyruvate oxidation by hepatocytes from HCCL-treated animals was linearly correlated with the citrate synthetase and carnitine palmitoyltransferase activities determined in the hepatocytes (Fig. 1), demonstrating that the increased oxidation capacity reflected increased mitochondrial content per hepatocyte.

An increased mitochondrial protein content per gram liver can result from an increased synthesis and/or a reduced breakdown of mitochondrial protein. As an index of mito- chondrial biogenesis, mitochondrial RNA content was compared in livers from control and 5-6-wk HCCL-treated rats. Total RNA was extracted, resolved by agarose gel electrophoresis, and probed with $\left[{ }^{32} \mathrm{P}\right] \mathrm{cDNA}$ representing the total mouse mitochondrial genome. Four major bands were visualized (Fig. 2) and densitometrically quantified on autoradiographs (Table VI). The bands were identified based on the migration on the agarose gel (33). Bands A (containing a precursor mRNA corresponding to the ND5/ND6/cytochrome $b$ region of the mitochondrial genome) and $B$ (containing a precursor mRNA corresponding to the ND5/ND6 region of the mitochondrial genome) were 3 and 10 times increased, respectively, in the RNA preparations from control and HCCLtreated animals. Band $C$ (composed of mitochondrial $16 \mathrm{~S}$ rRNA, and a precursor mRNA fragment corresponding to the

\section{Table IV. Hepatic Mitochondrial Protein Content}

\begin{tabular}{lccc}
\hline & & \multicolumn{2}{c}{ HCCL $(n=3)$} \\
\cline { 3 - 4 } $\begin{array}{c}\text { Enzyme used for } \\
\text { calculation }\end{array}$ & Control & Treated 2-3 wk & Treated 5-6 wk \\
\hline & \multicolumn{2}{c}{ mg mitochondrial protein/g liver } \\
Citrate synthetase & $59.1 \pm 10.1$ & $78.0 \pm 3.4^{*}$ & $80.0 \pm 12.0^{*}$ \\
$\begin{array}{l}\text { Glutamate } \\
\text { dehydrogenase }\end{array}$ & $104 \pm 19$ & $109 \pm 15$ & $137 \pm 64$ \\
$\begin{array}{l}\text { Succinate } \\
\text { dehydrogenase }\end{array}$ & $42.1 \pm 14.0$ & $56.1 \pm 7.8$ & $70.4 \pm 12.5^{*}$ \\
$\begin{array}{c}\text { Carnitine } \\
\text { palmitoyltransferase }\end{array}$ & $53.2 \pm 11.9$ & $67.3 \pm 7.9$ & $70.4 \pm 7.5^{*}$ \\
Average & $64.5 \pm 9.2$ & $77.7 \pm 2.2^{*}$ & $89.6 \pm 23.6^{*}$ \\
\hline
\end{tabular}

Liver mitochondrial protein content was calculated using the recovery of each mitochondrial enzyme in the mitochondrial preparations. For the calculations of the average, the mean protein content was calculated separately for each animal and the values averaged.

${ }^{*} P<0.05$ treated vs. control. No significant differences were present between the treated groups. 
Table V. Activity of Extramitochondrial Enzymes in Liver Homogenate

\begin{tabular}{|c|c|c|c|}
\hline \multirow[b]{2}{*}{ Enzyme } & \multirow[b]{2}{*}{ Control $(n=6)$} & \multicolumn{2}{|c|}{$\operatorname{HCCL}(n=3)$} \\
\hline & & Treated $2-3 \mathbf{w k}$ & Treated 5-6 wk \\
\hline & \multicolumn{3}{|c|}{$\mu \mathrm{moles} / \mathrm{min} / \mathrm{g}$ liver } \\
\hline Lactate dehydrogenase & $322 \pm 35$ & $315 \pm 14$ & $271 \pm 30$ \\
\hline Arylsulfatase A & $0.97 \pm 0.13$ & $1.13 \pm 0.16$ & $0.87 \pm 0.33$ \\
\hline Catalase* & $5.35 \pm 1.01$ & $5.34 \pm 0.16$ & $5.45 \pm 0.82$ \\
\hline $\begin{array}{c}\text { Cyanide insensitive } \\
\text { palmitoyl-CoA }\end{array}$ & & & \\
\hline oxidation & $0.059 \pm 0.005$ & $0.062 \pm 0.002$ & $0.056 \pm 0.002$ \\
\hline
\end{tabular}

To measure enzyme activities, $100 \mu$ l liver homogenate was mixed with $100 \mu \mathrm{l}$ cholate $5 \%(\mathrm{wt} / \mathrm{vol})$ and $800 \mu \mathrm{l} 0.1 \mathrm{M}$ potassium phosphate buffer, $\mathrm{pH}$ 7.2. Enzyme assays were performed as described in the text. $n=6$ for the control group and $n=3$ for each treated group. * Units are liters per minute per gram liver. No significant differences were present between treated and control animals or between the two groups of treated animals.

$\mathrm{ND4} / \mathrm{COI}$ region of the mitochondrial genome) was not different in the RNA preparations from control and HCCLtreated rats. Band D (containing $12 \mathrm{~S}$ rRNA and mRNA for ND1) was increased twofold in the RNA preparations from HCCL-treated rats compared with the controls.

\section{Discussion}

HCCL treatment induces a metabolic defect qualitatively identical to that seen in nutritional vitamin B12 deficiency and the inherited methylmalonic acidurias. In contrast to the severe metabolic derangements resulting from the acute accumulation of propionyl-CoA and methylmalonyl-CoA, chronic functional vitamin B12 deficiency is associated with grossly normal fuel homeostasis in vivo (4). The current studies demonstrate that mitochondrial capacity is increased during HCCL treatment, resulting in enhanced oxidative metabolism per hepatocyte and per gram of liver.
In comparison to hepatocytes isolated from control rats, and in agreement with previous studies (5), $\mathrm{CO}_{2}$ production from $1 \mathrm{mM}$ propionate by hepatocytes isolated from 5-6-wk HCCL-treated rats was decreased by $83 \%$, whereas $\mathrm{CO}_{2}$ production from pyruvate and palmitate were increased by $45 \%$ and $49 \%$, respectively. In contrast to the increased $\mathrm{CO}_{2}$ production, glucose production from pyruvate was not increased in hepatocytes from HCCL-treated rats as compared with cells from control animals. Based on the specific increase in mitochondrial oxidative capacity in hepatocytes isolated from $\mathrm{HCCL}$-treated rats, the differential effect on glucose and $\mathrm{CO}_{2}$ production from pyruvate may be due to the partial extramitochondrial localization of enzymes involved in gluconeogenesis (38). The increased oxidative metabolism of pyruvate and palmitate per hepatocyte could not be explained by an enhanced oxidative metabolism per milligram mitochondrial protein which was unaffected by HCCL treatment (Table I). Equal activities of extramitochondrial enzymes in mitochondrial preparations from control and HCCL-treated animals rule out the possibility that a higher mitochondrial metabolic activity in preparations from treated rats was masked by increased contamination with lysosomes and/or peroxisomes.

The increase in the activities of the mitochondrial enzymes per hepatocyte and per gram liver suggests that treatment with HCCL is associated with an increased amount of mitochondrial protein per gram liver tissue. Dietary vitamin B12 deficiency has been reported to increase liver citrate synthetase activity per gram liver tissue (39), consistent with the characteristics of the HCCL-treated rat reported here. Based on the recovery of mitochondrial enzymes, the average increase of mitochondrial protein per gram liver induced by HCCL treatment was $21 \%$ after $2-3 \mathrm{wk}$ and $39 \%$ after $5-6 \mathrm{wk}$ of treatment. The $39 \%$ increase in mitochondrial protein after 5-6 wk of HCCL treatment is in accord with the $45 \%$ and $49 \%$ increase in $\mathrm{CO}_{2}$ production from pyruvate and palmitate, respectively, by isolated hepatocytes. The HCCL-induced mitochondrial proliferation is similar to that reported for other inducers like valproate (40) and clofibrate (41). Interestingly, both valproate and clofibrate are organic acids and can be activated to form a coenzyme A derivative. Induction of mitochondrial proliferation may therefore be a common effect of intramitochondrial
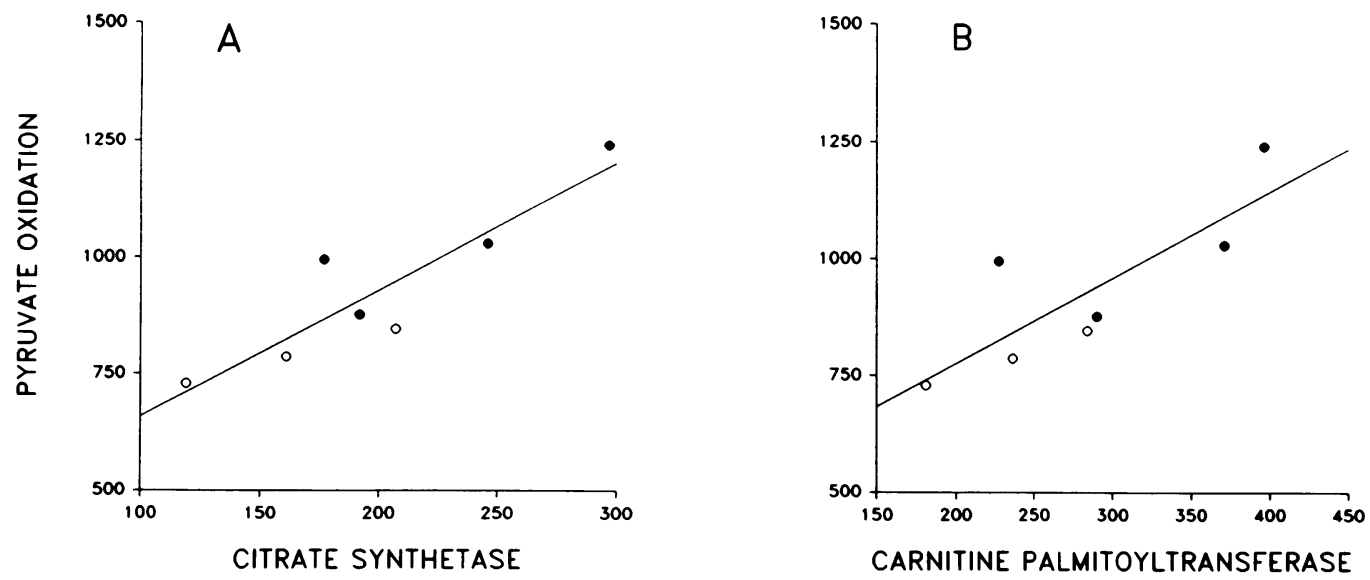

Figure 1. Relationship between citrate synthetase activity and pyruvate oxidation $(A)$ and between carnitine palmitoyltransferase activity and oxidative pyruvate oxidation $(B)$ in isolated hepatocytes from HCCL-treated rats. Each point represents a hepatocyte preparation from an individual animal. Animals treated for 2-3 wk are represented by open circles, and animals treated for 5-6 wk by closed circles. Enzyme activities are

given as nmoles/minute $/ 10^{6}$ cells and pyruvate oxidation rates as nmoles $/ 30$ minute $/ 10^{6}$ cells. There is a linear relationship between pyruvate oxidation and both enzyme activities. The regression equations are: $(A) y=387+2.7 x(r=0.91)$ and $(B) y=406+1.8 x(r=0.83)$. 

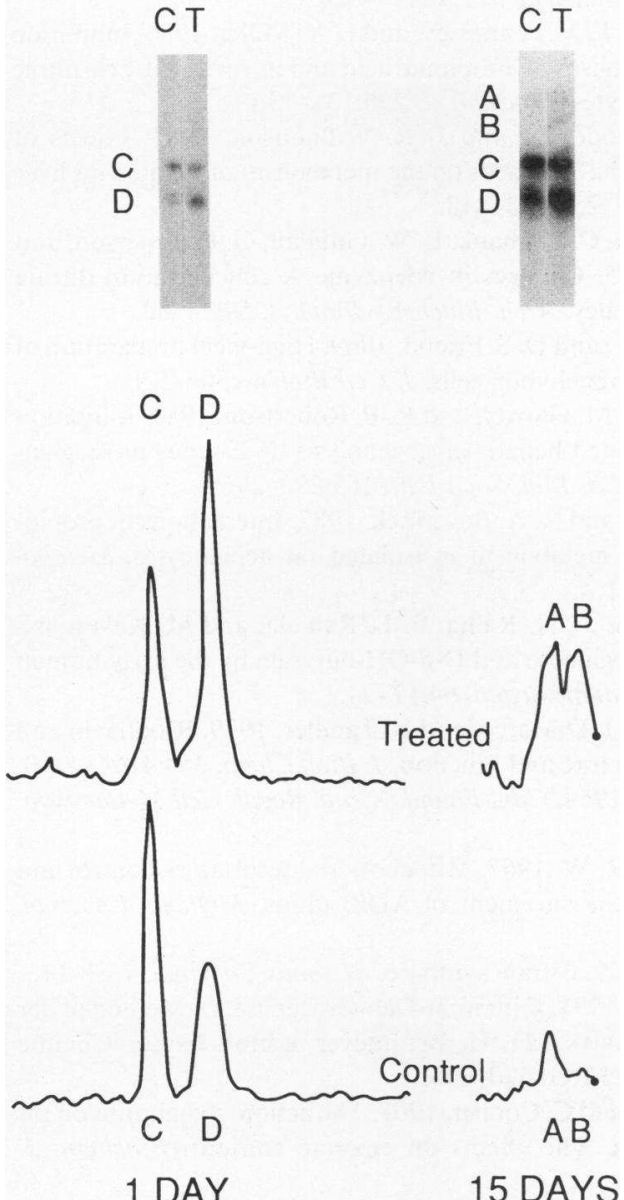

Figure 2. Northern blot hybridization analysis of total RNA extracted from liver tissue from control and from 5-6-wk HCCLtreated animals. $20 \mu \mathrm{g}$ of total liver RNA per animal was size fractionated by electrophoresis on a denaturing agarose gel. RNA was blotted onto nylon membranes and hybridized with $\left[{ }^{32} \mathrm{P}\right] \mathrm{cDNA}$ plasmid pAM1 that contains the entire mouse mitochondrial genome. The photographs shown are from x-ray films exposed for 1 and $15 \mathrm{~d}$. The corresponding densitometric tracings are shown in the lower panels. Band A contains precursor mRNA sequences corresponding to the ND5/ND6 cytochrome $b$ region of the mitochondrial genome. Band B contains precursor mRNA corresponding to the ND5/ND6 region of the mitochondrial genome. Band $C$ contains $16 \mathrm{~S}$ rRNA, and mRNA sequences from the ND4/COI region. Band D contains $12 \mathrm{~S}$ rRNA and mRNA for ND1.

accumulation of unusual acyl-CoAs. In contrast to clofibrate, which stimulates not only mitochondrial (41), but also peroxisomal biogenesis $(28,42)$, treatment with HCCL did not induce hepatic peroxisomal proliferation, as shown by equal activities of the two peroxisomal markers catalase and cyanideinsensitive palmitoyl-CoA oxidation in control and HCCL-treated rats expressed per gram liver (Table V). The lack of peroxisomal proliferation in HCCL-treated animals indicates that mitochondrial and peroxisomal biogenesis can be stimulated by independent mechanisms. While peroxisomes can oxidize long chain fatty acids (42), the lack of increase in cyanide-insensitive palmitoyl-CoA oxidation with
Table VI. Densitometric Analysis of Northern Blot Hybridizations from Hepatic RNA

\begin{tabular}{ccc}
\hline Band & $\begin{array}{c}\text { Control } \\
(n=3)\end{array}$ & Treated 5-6 wk \\
\hline A & $9.2 \pm 4.9$ & $31.3 \pm 11.6^{*}$ \\
B & $8.6 \pm 2.1$ & $87.9 \pm 22.8^{*}$ \\
C & $92.5 \pm 8.8$ & $69.9 \pm 11.9$ \\
D & $60 \pm 3$ & $128 \pm 14^{*}$
\end{tabular}

RNA $20 \mu \mathrm{g}$ extracted from liver tissue from control and 5-6-wk HCCL-treated animals was size fractioned by gel electrophoresis. The RNA was blotted onto nylon membranes and probed with the $\left[{ }^{32} \mathrm{P}\right] \mathrm{cDNA}$ plasmid pAM1 which contains the entire mouse mitochondrial genome. Two autoradiographs obtained from two different blots were analyzed using an Ultra Scan Densitometer. Four major bands were visualized on the blots. Band A contains mRNA sequences from the ND5/ND6 cytochrome $b$ region of the mitochondrial genome. Band B contains mRNA sequences from the ND5/ ND6 region. Band $C$ contains 16S rRNA and mRNA sequences from the ND4/COI region. Band D contains $12 \mathrm{~S}$ rRNA and mRNA for ND1. The data represent the AUC on the densitometric plots (unitless). The values of two different autoradiographs were averaged to give the mean AUC for each animal.

${ }^{*} P<0.05$ between the two groups.

HCCL treatment excludes peroxisomal $\beta$-oxidation as responsible for the increased palmitate oxidation in hepatocytes from HCCL-treated animals.

The underlying mechanism of an increased mitochondrial content can be enhanced synthesis of mitochondria, reduced breakdown, or a combination of both. The current studies show that HCCL treatment induces a 3-10-fold increase in precursor mitochondrial mRNA from the ND5/ND6/cytochrome $b$ region of the mitochondrial genome. Since synthesis has been suggested to be the regulating factor for the steady-state levels of rat liver mitochondrial mRNA (43), increased mRNA levels are consistent with an enhanced transcription of the mitochondrial genome. Another explanation for these findings may be a defect in processing of mitochondrial mRNA in HCCL-treated animals, since the bands visualized on the Northern blots represent mRNA precursors and not mRNA coding for a single mitochondrial protein. In hyperthyroid rats, a well-characterized animal model of hepatic mitochondrial proliferation (44), the same qualitative changes in the mitochondrial RNA pattern including preferential accumulation of precursor mRNAs, have been described as in the present investigation (45). The changes are consistent with enhanced mitochondrial synthesis as a mechanism that increases mitochondrial content in the HCCL-treated rat.

Mitochondrial proliferation may be a mechanism to counteract the inhibitory effect of accumulated acyl-CoAs on mitochondrial metabolism in order to maintain hepatocellular function. An increase in tissue mitochondrial content may be an important feature of cellular response to metabolic disease, and has also been observed in defects of the respiratory chain in humans (46-48). Another mechanism described in rats with cobalamin deficiency-induced methylmalonic aciduria is a higher CoA content per gram liver $(4,15)$. Both mechanisms develop over a period of weeks in vivo and can therefore not prevent acute toxicity due to hepatocellular buildup of pro- 
pionyl-CoA and methylmalonyl-CoA (9-14). During chronic accretion of acyl-CoAs induced by treatment with HCCL over $5 \mathrm{wk}$, however, these compensatory mechanisms may contribute to the relatively normal fuel homeostasis in these animals (4).

In conclusion, the present study shows that HCCL-induced methylmalonic aciduria is associated with increased hepatic mitochondrial capacity. This enhanced mitochondrial capacity may be a compensatory mechanism to maintain hepatocellular function in the presence of high intramitochondrial concentrations of toxic acyl-CoAs. The HCCL-treated rat provides a useful model for studying cellular responses in vivo and in vitro to a specific metabolic defect analogous to the defect in the human hereditary methylmalonic acidurias.

\section{Acknowledgments}

We thank Dr. Charles L. Hoppel for his helpful comments on the manuscript, Ms. J. Carpenter for typing the manuscript, Ms. K. Ring for performing the RNA purification and Mr. T. L. Lam for assistance with the gel electrophoresis and preparation of the Northern blots. The mouse c-DNA plasmid (pAM1) was kindly provided by Dr. David Clayton, Stanford University School of Medicine, Palo Alto, California.

This work was supported by the National Institutes of Health grants DK-36069 (E. P. Brass) and DK-37165 (S. P. Stabler). E. P. Brass is a Burroughs Wellcome Scholar in Clinical Pharmacology. S. Krahenbuhl was supported by a grant of the Swiss National Science Foundation.

\section{References}

1. Rosenberg, L. E., and W. A. Fenton. 1989. Disorders of propionate and methylmalonate metabolism. In The Metabolic Basis of Inherited Disease. C. R. Scriver, A. L. Beaudet, W. S. Sly, and D. Valle, editors. McGraw-Hill, New York. 821-844.

2. Cox, E. M., and A. M. White. 1962. Methylmalonic acid excretion: an index of vitamin B12 deficiency. Lancet. ii:853-856.

3. Stabler, S. P., P. D. Marcell, E. R. Podell, R. H. Allen, and J. Lindenbaum. 1986. Assay of methylmalonic acid in the serum of patients with cobalamin deficiency using capillary gas chromatography-mass spectrometry. J. Clin. Invest. 77:1606-1612.

4. Brass, E. P., A. G. Tahiliani, R. H. Allen, and S. P. Stabler. 1990. Coenzyme A metabolism in vitamin B12 deficient rats. J. Nutr. 120:290-297.

5. Brass, E. P., R. H. Allen, L. J. Ruff, and S. P. Stabler. 1990. Effect of hydroxy-cobalamin[c-lactam] on propionate and carnitine metabolism in the rat. Biochem. J. 266:809-815.

6. Stabler, S. P., P. D. Marcell, E. R. Podell, R. H. Allen, and J. Lindenbaum. 1984. Development of a new assay for methylmalonic acid in human and rat serum. Blood. 64(Suppl. 1):42a. (Abstr.)

7. Frenkel, E. P., and J. D. White. 1973. Characterization of an animal model of vitamin B12 deprivation. Lab. Invest. 29:614-619.

8. Brass, E. P., and S. P. Stabler. 1988. Carnitine metabolism in the vitamin B12-deficient rat. Biochem. J. 255:153-159.

9. Martin-Roquero, A., B. E. Corkey, S. Cordan, E. Walajtys-Rode, E., R. L. Parrilla, and J. R. Williamson. 1983. Interactions between alpha-ketoisovalerate metabolism and the pathways of gluconeogenesis and urea synthesis in isolated hepatocytes. J. Biol. Chem. 258:3673-3681.

10. Brass, E. P. 1986. Effect of alpha-ketobutyrate on palmitic acid and pyruvate metabolism in isolated rat hepatocytes. Biochim. Biophys. Acta. 888:18-24.

11. Glasgow, A. M., and H. P. Chase. 1976. Effect of propionic acid on fatty acid oxidation and ureagenesis. Pediatr. Res. 10:683-686.
12. Brass, E. P., and R. A. Beyerinck. 1988. Effect of propionate and carnitine on the hepatic oxidation of short- and medium-chainlength fatty acids. Biochem. J. 250:819-825.

13. Brass, E. P., P. V. Fennessey, and L. V. Miller. 1986. Inhibition of oxidative metabolism by propionic acid and its reversal by carnitine in isolated hepatocytes. Biochem. J. 236:131-136.

14. Walatjys-Rode, E., and J. R. Williamson. 1983. Effects of branched-chain alpha-ketoacids on the metabolism of isolated rat liver cells. J. Biol. Chem. 255:413-418.

15. Boxer, G. E., C. E. Shank, E. W. Gilfillan, G. H. Emerson, and E. L. Oginski. 1955. Changes in coenzyme A concentration during vitamin B12 deficiency. Arch. Biochem. Biophys. 59:24-32.

16. Berry, M. N., and D. S. Friend. 1969. High-yield preparation of isolated rat liver parenchymal cells. J. Cell Biol. 43:506-520.

17. Brass, E. P., M. Garrity, and R. P. Robertson. 1984. Inhibition of glucagon-stimulated hepatic glycogenolysis by E-series prostaglandins. FEBS (Fed. Eur. Biol. Soc.) Lett. 169:293-296.

18. Brass, E. P., and R. A. Beyerinck. 1987. Interactions of propionate and carnitine metabolism in isolated rat hepatocytes. Metabolism. 36:781-787.

19. Adam, P. A. J., N. Raiha, E. L. Rahiala, and M. Kekomaki. 1975 . Oxidation of glucose and D- $\beta-\mathrm{OH}$-butyrate by the early human fetal brain. Acta Pediatr. Scand. 64:17-24.

20. Hoppel, C., J. DiMarco, and B. Tandler. 1979. Riboflavin and rat hepatic cell structure and function. J. Biol. Chem. 254:4164-4170.

21. Chance, B. 1959. Ciba Found. Symp. Regul. Cell Metabolism. 91-129.

22. Estabrook, R. W. 1967. Mitochondrial respiratory control and the polarographic measurement of ADP: ratios. Methods Enzymol. 10:41-47.

23. Srere, P. 1969. Citrate synthase. Methods Enzymol. 13:3-11.

24. Schmidt, E. 1971. Glutamat-Dehydrogenase. In Methoden der Enzymatischen Analyse. H. U. Bergmeyer, editor. Verlag Chemie GmbH, Weinheim, FRG. 690-695.

25. Hoppel, C., and C. Cooper. 1968. The action of digitonin on rat liver mitochondria. The effects on enzyme content. Biochem. $J$. 107:367-375.

26. Hoppel, C., and R. Tomec. 1972. Carnitine palmitoyltransferase. J. Biol. Chem. 247:832-841.

27. Aebi, H. 1983. Catalase. In Methods of Enzymatic Analysis. Vol. III. H. U. Bergmeyer, editor. Verlag Chemie GmbH, Weinheim, FRG. 273-286.

28. Gray, T. J. B., B. G. Lake, T. A. Beamand, J. R. Foster, and S. D. Gangetti. 1983. Peroxisome proliferation in primary cultures of rat hepatocytes. Toxicol. Appl. Pharmacol. 67:15-25.

29. Baum, H., K. S. Dodgson, and B. Spencer. 1959. The assay of arylsulfatases A and B in human urine. Clin. Chim. Acta. 4:453-455.

30. Vassault, A. 1983. Lactate dehydrogenase. In Methods of Enzymatic Analysis. Vol. III. H. U. Bergmeyer, editor. Verlag Chemie GmbH, Weinheim, FRG. 118-125.

31. Gornall, A. G., G. J. Bardawill, and M. M. David. 1949. Determination of serum proteins by means of the biuret reaction. J. Biol. Chem. 177:751-766.

32. Ray, D. B., R. W. Jansen, I. A. Horsl, N. C. Mills, and J. Kowal. 1986. A complex noncoordinate regulation of $\alpha$-lactalbumin and $25 \mathrm{~K}$ $\beta$-casein by corticosterone, prolactin, and insulin in long-term cultures of normal rat mammary cells. Endocrinology. 118:393-407.

33. Van Elten, R. A., N. L. Michael, M. J. Bibb, A. Brennicke, and D. A. Clayton. 1983. Expression of the mouse mitochondrial DNA genome. In Mitochondrial Genes. P. Slonimski, P. Borst, and G. Attardi, editors. Cold Spring Harbor Monogr. Ser. 73-88.

34. Ziegler, H.J., P. Bruckner, and F. Binon. 1967. O-acetylation of dl-carnitine chloride. J. Org. Chem. 32:3989-3991.

35. Binder, M., J. F. Kolhouse, K. C. van Horne, and R. H. Allen. 1982. High-pressure liquid chromatography of cobalamins and cobalamin analogs. Anal. Biochem. 125:253-258.

36. Dolphin, D. 1971. Preparation of the reduced forms of vitamin 
B12 and of some analogues of the vitamin B12 coenzyme containing a cobalt-carbon bond. Methods Enzymol. 18:34-52.

37. Armitage, P., and G. Berry. 1987. Statistical Methods in Medical Research. Second Ed. Blackwell Scientific Publication, Oxford/ London/Edinburgh.

38. Pilkis, S. J., M. R. El-Maghrabi, and T. H. Claus. 1988. Hormonal regulation of hepatic gluconeogenesis and glycolysis. Annu. Rev. Biochem. 57:755-783.

39. Frenkel, E. P., A. Mukherjee, C. R. Hackenbrock, and P. A. Srere. 1976. Biochemical and ultrastructural hepatic changes during vitamin B12 deficiency in animals and man. J. Biol. Chem. 251:2147-2154.

40. Hayaska, K., I. Takahashi, Y. Kobayashi, K. Iinuma, K. Narisawa, and K. Tada. 1986. Effects of valproate on biogenesis and function of liver mitochondria. Neurology. 36:351-356.

41. Gear, A. R., A. D. Albert, and J. M. Bednarek. 1974. The effect of the hypocholesterolemic drug clofibrate on liver mitochondrial biogenesis. J. Biol. Chem. 249:6495-6504.

42. Lazarow, P. B., and C. DeDuve. 1976. A fatty acyl-CoA oxidizing system in rat liver peroxisomes; enhancement by clofibrate, a hypolipidemic drug. Proc. Natl. Acad. Sci. USA. 73:2043-2046.

43. Cantatore, P., Z. Flagella, F. Fracasso, A. M. Lezza, M. N.
Gadaleta, and A. de Montalvo. 1987. Synthesis and turnover rates of four rat liver mitochondrial RNA species. FEBS (Fed. Eur. Biol. Sci.) Lett. 213:144-148.

44. Fringes, B., and A. Reith. 1982. Time course of peroxisome biogenesis during adaptation to mild hyperthyroidism in rat liver. $L a b$. Invest. 47:19-26.

45. Mutrei, A., S. Kuzela, and B. D. Nelson. 1989. Control of mitochondrial transcription by thyroid hormone. Eur. J. Biochem. 1801:235-240.

46. Haller, R. G., S. F. Lewis, R. W. Estabrook, S. DiMauro, S. Servidei, and D. W. Foster. 1989. Exercise intolerance, lactic acidosis, and abnormal cardiopulmonary regulation in exercise associated with adult skeletal muscle cytochrome c oxidase deficiency. J. Clin. Invest. 84:155-161.

47. Hayes, D. J., B. R. F. Lecky, D. N. Landon, J. A. MorganHughes, and J. B. Clark. 1984. A new mitochondrial myopathy. Biochemical studies revealing a deficiency in the cytochrome $b-c_{1}$ complex (complexIII) of the respiratory chain. Brain. 107:1165-1177.

48. Hoppel, C. L., D. S. Kerr, B. Dahms, and U. Roessmann. 1987. Deficiency of the reduced nicotinamide adenine dinucleotide dehydrogenase component of complex I of mitochondrial transport. J. Clin. Invest. 80:71-77. 